\title{
Experimental System and Tests to Optimize a Tomato Drying Process
}

\author{
P. Catalano, F. Fucci, F. Giametta, A. La Penna and G. La Fianza* \\ University of Molise, Department of S.A.V.A, Via De Sanctis, 86100, Campobasso, Italy
}

\begin{abstract}
The aim of the current work is to give a contribution to the study of the drying process of tomatoes through the synergy of the hot air and microwave technologies. The drying of tomatoes is a process commonly used to preserve the product and to prolong its shelf-life. In this paper, four experimental tests on the product under study, were carried out. Then, different drying diagrams were developed and analyzed taking into account the conventional air system, the microwave system and the simultaneous use of hot air and microwaves. The drying tests were carried out using the "Cencara" tomatoes type.
\end{abstract}

Keywords: Vegetables through, Hot air, Microwave technologies.

\section{INTRODUCTION}

The drying of tomatoes is a process commonly used to preserve the product and to prolong its shelf-life. However, tomatoes dried under natural conditions may be exposed to dust, rain and high temperatures. In these conditions some problems can determine a worsening of the quality of the final products. These problems are: crack of the structure, bleaching, hard texture, loss of flavour and nutritional properties, low rehydration capacity, non-enzymatic browning [1]. In spite of that, a rising attention to the production of dried tomatoes is clear owing to the several ways their use and cooking [2]. Therefore, there is a rising demand by the consumer of finished products having their nutritional and sensorial characteristics preserved as much as possible. The experimental and industrial research turns its attention to optimization of the tomato drying process [3-6]. Many papers on single method dehydration have been published recently [7-10], but not so many evaluate effects of combined drying process $[10,11]$, especially on tomatoes [12-14], and in particular using microwave drying $[13,15]$.

In this study, the combination of microwave and convection processes to tomato was analysed with the intent to improve the sensorial quality and shelf-life of food, to speed up and to reduce drying time with consequent energy savings and reduction of management costs compared to the hot air drying process [16-19]. In particular, the aim of the present experimental work was to investigate the drying behavior of the system considering this particular kind of tomato Cencara cultivated in Southern and Central Italy. The choice of this product to be treated, was done considering its typicalness. The effective setting-up of the drying plant is specific for these particular samples of products (cut in half) considering the use of the final products. (These kind of tomatoes are often eaten after an under oil preservation).

*Address correspondence to this author at the University of Molise, Department of S.A.V.A Via De sanctis, 86100, Campobasso, Italy;

Tel: +3908744041; Fax: +39087440800; E-mails: lafianza@unimol.it, lafianza@libero.it
A wide demand from the customer at local and national level regarding this kind of product, determined the decision to use this system for its production. At the same time, the quality valorisation of the product may be carried out also using suitable traceability systems. Within some agro-food areas, the traceability becomes a must especially to enhance local product.

\section{MATERIALS AND METHODS}

\subsection{Experimental System}

In this paper, experimental tests on the product under study, were carried on. Different drying diagrams were developed and analysed taking into account the conventional air system, the microwave system and the simultaneous use of hot air and microwaves. Treatment with microwaves is an indirect heating method. Microwaves penetrate the food exciting molecules with permanent dipoles (water, amino acids, peptides) and transforming their kinetic energy into intermolecular friction with consequent heat generation. Microwave energy can be applied successfully in several processes in the food industry because the resulting volumetric heating of the product allows a slower heat transfer from the surface towards the centre of the product if compared with convective drying.

The drying tests were carried out using tomatoes $\mathrm{Cv}$. "Cencara". The drying plant (designed by the Microglass s.r.l. firm) consists of a batch type machine having external dimensions of $170 \times 120 X 245 \mathrm{~cm}$. Internally there is a cylindrical hollow with $90 \mathrm{X} 140 \mathrm{~cm}$ centerline section and volume of 1 cubic meters (Fig. 1a,b). Within the plant there is a steel trolley with 5 rotating $(4.6 \mathrm{rpm})$ carriages where product to be treated can be placed.

The plant is characterized by 2 drying systems:

1) hot air convection system

2) microwave system (MW) 


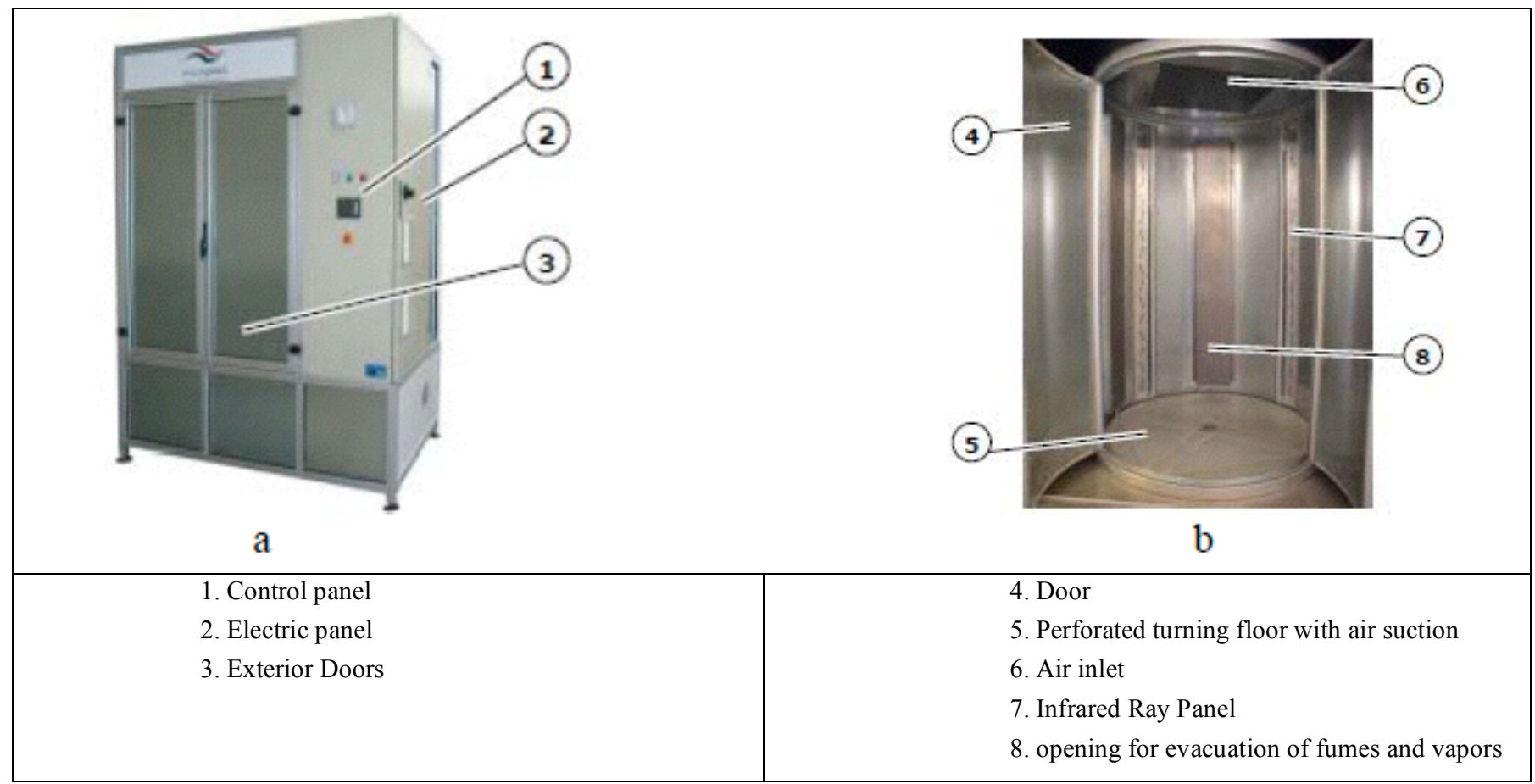

Fig. (1). Drying system: a) external view; b) internal view.

Table 1. Fan Technical Characteristics

\begin{tabular}{|c|c|}
\hline Fan Power & $\mathbf{1 . 3} \mathbf{k W}$ \\
\hline \hline Rate - speed $(100 \%)$ & $\sim 8100 \mathrm{~m}^{3} / \mathrm{h}-0.8 \mathrm{~m} / \mathrm{s}$ \\
\hline Rate - speed $(70 \%)$ & $\sim 800 \mathrm{~m}^{3} / \mathrm{h}-0.5 \mathrm{~m} / \mathrm{s}$ \\
\hline Rate - speed $(40 \%)$ & $\sim 600 \mathrm{~m}^{3} / \mathrm{h}-0.3 \mathrm{~m} / \mathrm{s}$ \\
\hline Air change & $60 \mathrm{~m}^{3} / \mathrm{h}($ open chimney 8$)$ \\
\hline
\end{tabular}

Process parameters are set and controlled via a PLC (Programmable logic controller) that allows to set: drying cycles, stages (maximum 4), duration and of the desired sequence of any of the 2 above-mentioned drying systems. Starting cycle mode can also be set among the following options:

IMMEDIATE - the cycle starts immediately;

TEMPERATURE - the sequence starts after the machine has reached the set temperature in the first drying phase;

FAN ON/OFF: OFF mode switches off both the recirculation fan and the heating during the first phase.

\subsection{Hot Air Convection System}

Airflow is achieved via a closed circuit, consisting of a centrifugal fan and an electrical heater battery. An inverter controls the centrifugal fan speed, allowing power adjustment (from $40 \%$ to 100) as shown in Table 1.

Centrifugal fan speed is controlled by an inverter that allows power adjustment (from $40 \%$ to 100 ) as shown in Table 1.

The air inlet is at the top of the hollow, while the air outlet is at its bottom. The air circuit has an adjustable opening allowing the partial evacuation of fumes and vapors. The air heating system is based on electric resistance coils for a total absorbed power of $9.6 \mathrm{~kW}$, allowing a maximum air temperature of $90^{\circ} \mathrm{C}$.

\subsection{Microwave System}

The system consists of 2 microwave magnetron, each one with adjustable power as follows: $0.5-1-1.5-2 \mathrm{~kW}$, for a total capacity of up to $4 \mathrm{~kW}$. The microwave process allows to evacuate the deep moisture thanks to its high waves penetration power inside the product.

\subsection{Experimental Test}

The experimental tests were carried out on 4 different drying cycles each one repeated 2 times to have a feedback of the obtained results, precisely:

- the "Air" cycle (air speed: $0.8 \mathrm{~m} / \mathrm{s}$, air temperature: $\left.70^{\circ} \mathrm{C}\right)$;

- the combined microwave + air (series "MW + Air 1") with air speed: $0.8 \mathrm{~m} / \mathrm{s}$, air temperature: $40^{\circ} \mathrm{C}$ and microwave power equal to $2 \mathrm{~kW}$;

- a second combined microwave + air process (series "MW + Air 2") with air speed: $0.3 \mathrm{~m} / \mathrm{s}$, air temperature: $30^{\circ} \mathrm{C}$ and microwave power equal to $3 \mathrm{~kW}$;

- $\quad$ microwave power equal to $3 \mathrm{~kW}$; 


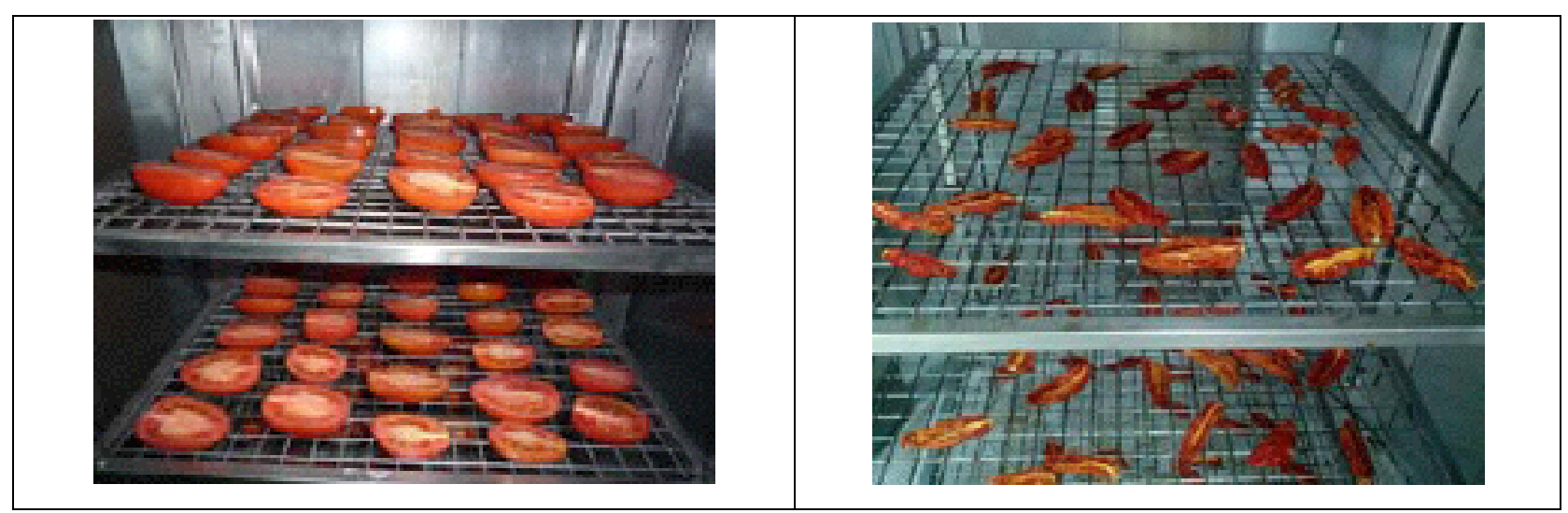

Fig. (2a). Fresh tomatoes inside the plant (2b). Dried tomatoes at the end of the treatment.

Table 2. Length Cycles Comparison

\begin{tabular}{|c|c|c|c|c|c|c|c|}
\hline \multirow[t]{2}{*}{ Cycle } & \multirow[t]{2}{*}{ Drying Process } & \multicolumn{2}{|c|}{$\begin{array}{c}\text { Duration } \\
\text { (min) }\end{array}$} & \multicolumn{2}{|c|}{$\begin{array}{c}\text { Absolute Variation } \\
\qquad(\mathrm{min})\end{array}$} & \multicolumn{2}{|c|}{$\begin{array}{c}\text { Relative Variation } \\
(\%)\end{array}$} \\
\hline & & 1st & 2nd & 1 st & 2nd & $1 \mathrm{st}$ & 2nd \\
\hline Air & Air & 720 & 780 & N.A. & - & - & - \\
\hline MW+Air1 & Microwave and Air (combined) & 360 & 330 & 360 & 450 & 50 & 58 \\
\hline MW & Microwave (air during final phase) & 300 & 300 & 420 & 480 & 58 & 62 \\
\hline MW+Air2 & Microwave then Air & 510 & 540 & 210 & 240 & 29 & 31 \\
\hline
\end{tabular}

Tomatoes were cut in half and placed on the trolley shelves inside the treatment cavity. Between one drying cycle and the next tomatoes position was changed in order to achieve a more uniform heat treatment. The tomatoes were dried from initial water activity equal to 1 (fresh tomatoes) to final values of $0.60+/-0.05$ in order to have stable products at refrigeration temperature $\left(4^{\circ} \mathrm{C}-5^{\circ} \mathrm{C}\right)$ (Fig. 2a,b).

The quantity of employed tomato in each test was $8 \mathrm{~kg}$. Initial weight of fresh product, its weight at the end of each drying phase and the final weight of the dried tomatoes were collected for each trial. Some preliminary quality characteristics such as the initial surface of fresh tomatoes, the final surface of dried tomato and the percentage variation of the surface were evaluated to quantify the shrinkage in relation to heat-treatment.

The tomatoes sizes were calculated through dimensional measurements which have taken into account the initial and the final areas and the variations of the areas as reported in Table 3. Colour was determined on the surface of tomato using the Hunter $\mathrm{L}^{*}, \mathrm{a}^{*}, \mathrm{~b}^{*}$ system with a reflectance spectrophotometer (Minolta CR300b, Suita-shi, Osaka, Japan). Aw was determinated (AQUALAB Tecnologies) and acidity (O.J. 229/86). pH was measured by means of a Crison 2001 series (Crison Instrument, Alella, Spain).

Finally, a random selection of $100 \mathrm{~g}$ of samples were frozen in nitrogen and ground in a Waring blender. About 5 $\mathrm{g}$ of the residue were extracted twice with $50 \mathrm{ml}$ of watermethanol $(40: 60, \mathrm{v} / \mathrm{v})$ under magnetic stirring for $30 \mathrm{~min}$ at $4^{\circ} \mathrm{C}$ : an aliquot was added to $5 \mathrm{ml}$ of the Folin-Ciocalteu reagent, $15 \mathrm{ml}$ of a $\mathrm{CaCO} 3$ solution $(10 \% \mathrm{w} / \mathrm{w})$, and placed in darkness for $90 \mathrm{~min}$ at $30^{\circ} \mathrm{C}$. Total phenols were determined colorimetrically at $760 \mathrm{~nm}$ (spectrophotometer Perkin
Elmer, mod. Lambda Bio 40) and expressed as catechin equivalents.

\section{RESULTS AND DISCUSSION}

Referring to the first set duration, the "Air" cycle which adopts only air drying system, needed 720 minutes (12.00 hours), while the combined microwave + air (series "MW + Air 1"), with microwave power equal to $2 \mathrm{~kW}$, required total drying time of 360 minutes (6.00 hours). Percentage reduction of treatment time equal to $50 \%$, i.e. the time of heat treatment was halved as shown in Table 2 . The "MW" cycle, using microwave powers equal to $4 \mathrm{~kW}$, further reduced treatment time. From 720 minutes of the convective system down just to 300 minutes ( 5 hours). Therefore, the percentage of time variation amounts to $58 \%$, i.e. the time required from the cycle "MW" is approximately $42 \%$ of the time employed by the traditional system. The "MW+Air2" cycle helped to bring treatment times from 720 minutes (12.00 hours) of the cycle "Air" to 510 minutes ( 9.00 hours) with a reduction of $29 \%$ of the total time. A more accurate analysis shows that the "Air" cycle and the "MW + Air1" cycle have a similar performance up to approx. 180 minutes, as a weight loss of approximately $45 \%$ is achieved in both cases.

Referring to the second set duration, the "Air" cycle which adopts only air drying system, needed 780 minutes (13.00 hours), while the combined microwave + air (series "MW + Air 1"), with microwave power equal to $2 \mathrm{~kW}$, required total drying time of 330 minutes (5.30 hours). Percentage reduction of treatment time equal to $58 \%$, i.e. the time of heat treatment was more than halved as shown in Table 2. The "MW" cycle, using microwave powers equal to $4 \mathrm{~kW}$, further reduced treatment time. From 720 minutes of 
Table 3. Energy Analysis

\begin{tabular}{|c|c|c|c|c|c|}
\hline Cycle & Electric Heaters (kJ) & Microwave (kJ) & Supplied Energy (kJ) & Product Weight (kg) & Specifyc Energy (kJ/kg) \\
\hline \hline Air & 328320 & 0 & 328320 & 7,9 & 41560 \\
\hline MW+Air1 & 27360 & 24840 & 52200 & 8,0 & 6525 \\
\hline MW & 55814 & 30240 & 86054 & 7,9 & 10890 \\
\hline MW+Air 2 & 193709 & 17280 & 210989 & 8,1 & 26050 \\
\hline
\end{tabular}

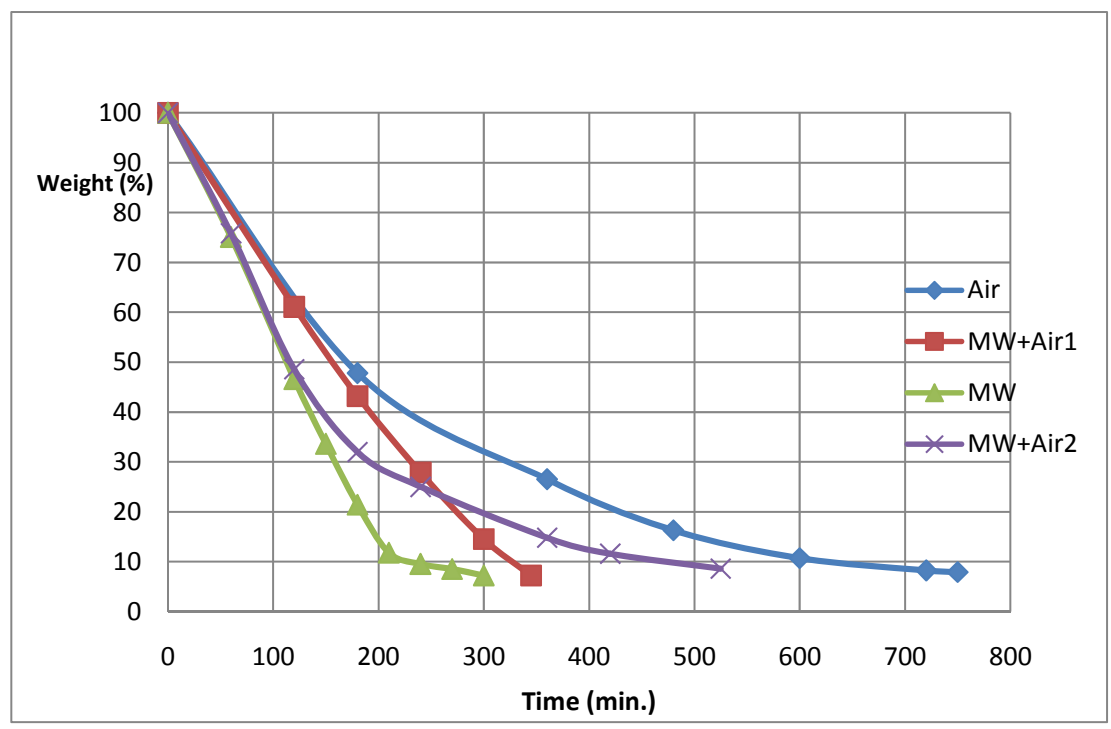

Fig. (3). Drying curves comparison (first and second series.

Table 4. Measured Area of Tomatoes

\begin{tabular}{|c|c|c|c|c|}
\hline Cycle & $\begin{array}{c}\text { Initial Area }\left(\mathbf{c m}^{2}\right) \\
\text { (Mean-Std. Dev.) }\end{array}$ & $\begin{array}{c}\left.\text { Final Area } \mathbf{( c m}^{2}\right) \\
\text { (Mean-Std. Dev.) }\end{array}$ & $\begin{array}{c}\text { Absolute Surface Variation (cm }) \\
\text { (Mean - Std. Dev.) }\end{array}$ & $\begin{array}{c}\text { Relative Surface Variation }(\%) \\
(\text { Mean) }\end{array}$ \\
\hline \hline Air & $33.8-0.63$ & $12.7-2.55$ & $21.1-1.92$ & 62.4 \\
\hline MW+Air 1 & $31.9-0.14$ & $13.7-0.35$ & $18.3-0.49$ & 57.2 \\
\hline MW & $33.9-0.57$ & $16.5-3.82$ & $17.4-4.38$ & 51.3 \\
\hline MW+Air2 & $32.9-1.27$ & $11.6-0.21$ & $21.3-1.06$ & 64.7 \\
\hline
\end{tabular}

the convective system down just to 300 minutes (5 hours). Therefore, the percentage of time variation amounts to $62 \%$, i.e. the time required from the cycle "MW" is approximately $38 \%$ of the time employed by the traditional system. The "MW+Air2" cycle helped to bring treatment times from 780 minutes (13.00 hours) of the cycle "Air" to 540 minutes (9.00 hours) with a reduction of $31 \%$ of the total time.

As said above the microwave system can greatly reduce drying time compared to the traditional system. Fig. (3) shows the drying curves of the four drying cycles (first series): in the early treatment phase (weight loss $<45 \%$ ) the "MW" and "MW + Air2" curves are characterized by the highest slope and the weight loss value of $45 \%$ is reached within 120 minutes against the 180 minutes of the first two treatments (Air and MW+Air1).

During the following phase of the drying process (weight loss $>45 \%$ ) the "MW" cycle remains the fastest compared to the other ones. The cycle "MW + Air 1" arises in an inter- mediate situation. The cycle "MW + Air2" shows a similar trend to the cycle "MW" until microwave modules are used. The slope of the corresponding curve ("MW + Air2") decreases remarkably after MW modules deactivation, canceling nearly all the advantages initially achieved, causing an increase of the treatment time which results higher than the "MW+Air1" cycle.

With reference to the average duration of each drying cycle was carried out an approximate energy analysis that wants to show a comparison of energy consumption resulting from the drying techniques adopted (Table 3 ).

Experimental tests have also shown a curling effect in tomatoes when using "Air" cycle; it looks absent in products treated using microwave (MW + Air 1" and "MW cycles"). In fact tomatoes treated by both microwave cycles are characterized by a larger surface and they appear completely flat. Tomatoes processed using the cycle "MW + Air2" present an aspect similar to that detected in products treated with 
Table 5a. Color Characteristics for Dried Tomatoes

\begin{tabular}{|c|c|c|c|}
\hline Samples & L*(luminosity) & $\mathbf{a}^{*}$ (Red Index) & $\mathbf{b}^{*}$ (Yellow Index) \\
\hline \hline 1(MW+Air1) & $34,5 \pm 1,0$ & $16,2 \pm 0,5$ & $23,6 \pm 1,7$ \\
\hline 2 (Air) & $33,3 \pm 1,2$ & $15,4 \pm 0,1$ & $23,2 \pm 1,2$ \\
\hline 3 (MW) & $34.9 \pm 1,9$ & $14,6 \pm 1,1$ & $24,8 \pm 2,8$ \\
\hline 4 (MW+Aria2) & $32,0 \pm 1,1$ & $16,1 \pm 0,7$ & $24,2 \pm 1,5$ \\
\hline
\end{tabular}

$*_{\mathrm{g}}$ acid citric/100 g DM (dry matter)

Table 5b. Chemical and Color Characteristics for Fresh Tomatoes

\begin{tabular}{|c|c|c|c|}
\hline Moisture & pH & Total Acidity & Color \\
\hline \hline$(\%)$ & & (g. di ac. citric/100 g.DM) & $\mathrm{L}^{*} \mathrm{a}^{*} \mathrm{~b}^{*}$ \\
\hline $92,7 \pm 0,5$ & $4,5 \pm 0,6$ & $2,25 \pm 0,9$ & $39,0 \pm 1,5^{*} 17,7 \pm 0,9 * 22,0 \pm 1,3 *$ \\
\hline
\end{tabular}

$*_{\mathrm{g}}$ acid citric/100 g DM (dry matter)

Table 5c. Chemical and Color Characteristics for Dried Tomatoes

\begin{tabular}{|c|c|c|c|c|}
\hline Samples & Moisture & pH & Total Acidity* & Total Polyphenols \\
\hline & $\mathbf{( \% )}$ & & & (g. of Catechin/Kg. s.s.DM) \\
\hline \hline 1 (MW = Aria 1) & $19,7 \pm 0,6$ & $3,9 \pm 0,05$ & $5,6 \pm 1,9$ & $8,3 \pm 3,4$ \\
\hline 2 (Aria 1) & $24,3 \pm 0,8$ & $3,8 \pm 0,12$ & $5,3 \pm 1,2$ & $6,8 \pm 2,5$ \\
\hline 3 (MW1) & $22,2 \pm 1,0$ & $4,0 \pm 0,02$ & $3,8 \pm 0,3$ & $3,7 \pm 0,2$ \\
\hline 4(MW\#Aria1) & $21,8 \pm 0,5$ & $3,94 \pm 0,13$ & $4,53 \pm 1,2$ & $4,86 \pm 0,5$ \\
\hline
\end{tabular}

$*_{\mathrm{g}}$ acid citric/100 g DM (dry matter)

"Air"cycle. The surfaces of the products were quantified using dimensional measurements that take into account the initial areas, the final areas and changes as shown in Table 4. These results show that the microwave cycle "MW + Air 1" $(2 \mathrm{~kW})$ determines a minor variation of the surface of the product $(57 \%$ versus $62 \%)$ which reduces shrinkage of the product of about $5 \%$ compared to the conventional system (Air). The cycle "MW", that uses higher MW power $(4 \mathrm{~kW})$ further reduces the variation of product surface $(51 \%$ versus $62 \%$ ) allowing to also reduce product shrinkage of approximately $11 \%$ against the "Air" system. The cycle "MW +Air 2 " causes a greater variation of product surface $(65 \%)$ than all other cycles and, therefore, a greater shrinkage of dried product.

As regards the color, tomatoes processed using the "Air" cycle and "MW + Air 2" cycle are quite similar. Dried tomatoes through the "MW" cycle were found to be qualitatively better as characterized by a more vivid red shade. In some tomato samples, generally treated with microwaves, bulges, color variations and burns may be observed.

The results are showed in Table $\mathbf{5 a}, \mathbf{b}, \mathbf{c}$ for dried and fresh tomatoes. Other characteristics evaluated were inner aspect, outer aspect and flavour. The number of replicate experiments undertaken to produce the data presented was three. The product samples were served at room temperature.

These negative aspects can be further reduced by optimizing the treatment cycle. Referring to consistency, tomatoes processed using "Air" and " MW + Air2" cycle appear

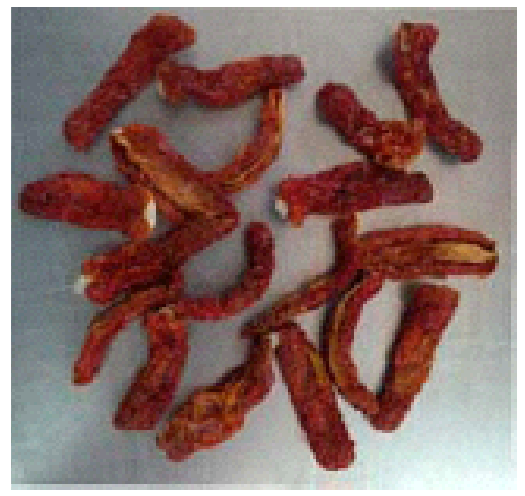

Fig. (4a). "Air" cycle.

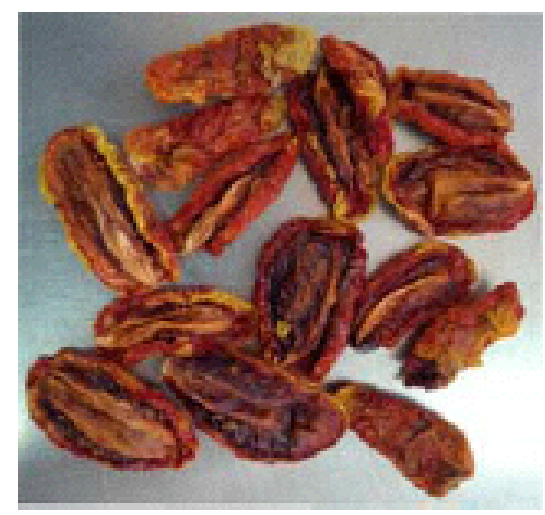

Fig. (4b). "MW+Air 1" cycle. 


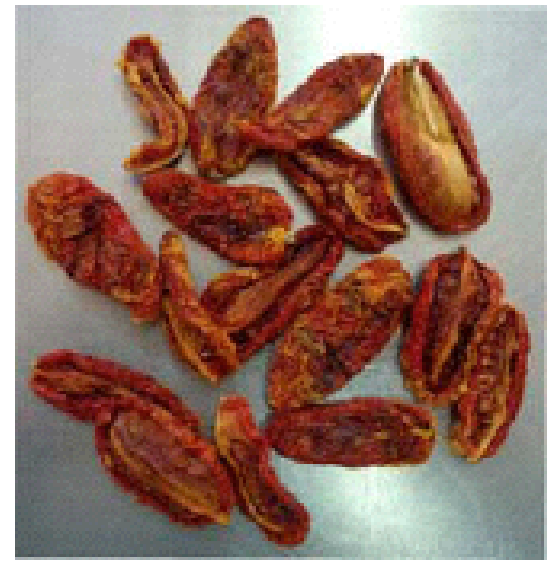

Fig. (4c). "MW" cycle.

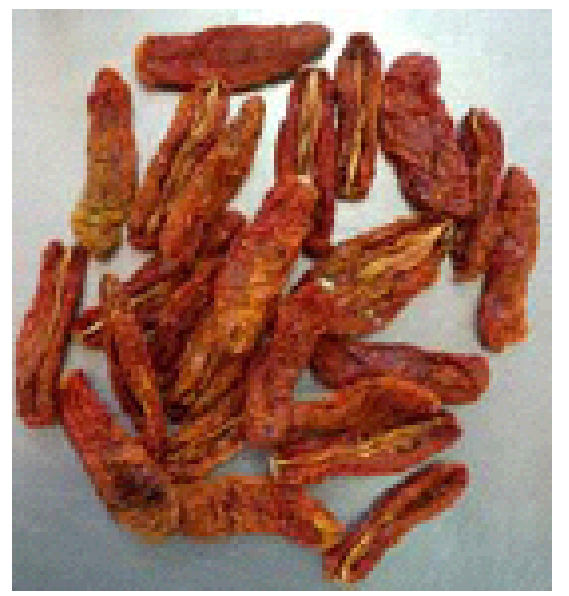

Fig. (4d). "MW+Air 2" cycle.

similar. Dried tomatoes obtained using the cycle "MW" were found to be softest ever. Ultimately, examined quality parameters highlighted that the tomatoes dried by microwave cycle "MW" (4 kW) are of better quality. We report below the frames of dried products (Fig. $4 \mathbf{a}, \mathbf{b}, \mathbf{c}, \mathbf{d})$.

\section{CONCLUSIONS}

In the present paper, the results obtained by drying tests allowed a comparison between different drying cycles. It can be assessed that the drying technology using microwave turns out to be advantageous in terms of heat treatment time. However, it is necessary to deepen the treated aspects, making use of accurate instrumental methodologies, in order to have more information and to obtain a complete evaluation of the product and on the plant $[7,12,13,20,21]$. The usefulness of computational thermo-fluid-dynamic for assessing the influence of the position of the product on the performance of the system could be taken into account for a future study $[8,22,23]$. The trolleys and tomatoes arranged on tiers caused an obstacle to the ventilation and to the thermal flow. This situation implied changes in the position of the product during the drying process causing, in some cases, problems of an inhomogeneous drying of tomatoes.

A future study might be the use of the system also on other types of product to locate and correct the causes of the heterogeneous development of microwaves in the treatment cavity.

\section{CONFLICT OF INTEREST}

The authors confirm that this article content has no conflicts of interest.

\section{ACKNOWLEDGEMENTS}

Declared none.

\section{REFERENCES}

[1] Cernîşev S. Effects of conventional and multistage drying processing on non-enzymatic browning in tomato. J Food Eng 2010; 96: 114-18.

2] McMinn WAM, Magee TRA. Principles methods and applications of the convective drying of foodstuffs. Food Bioprod Process 1999; 77(3):175-93.

[3] Carcel JA, Garcia-Perez JV, Riera E, Mulet A. Influence of highintensity ultrasound on drying kinetics of persimmon. Dry Technol 2007; 25(1): 185-93.

Clemente G, Bon J, Garcia-Perez JV, Mulet A. Natural convection drying at low temperature of previously frozen salted meat. Dry Technol 2007; 25(11): 1885-91.

] Riahi MH, Trelea IC, Leclercq-Perlat MN, Piacque D, Corrieu G. Model for changes in weight and dry matter during the ripening of a smear soft cheese under controlled temperature and relative humidity. Int Dairy J 2007; 17(8): 946-53.

Nogaya K, Li Y, Jin Z, Fukumuro M, Ando Y, Akaishi A. Low temperature desiccant-based food drying system. J Food Eng 2006; 75: $71-7$.

7] Hernandez-Perez JA, Garcia-Alvarado MA, Trystram G, Heyd B. Neural networks for the heat and mass transfer prediction during drying of cassava and mango. Innov Food Sci Emerg Technol 2004; 5(1): 57-64.

Brunetti L, Fucci F, La Fianza G. Un impianto di stagionatura a deumidificazione per assorbimento per alimenti. L Termotecnica 2004; LVII, 4: 68-71.

Corrêa PC, Horta de Oliveira GH, Machado Baptestini F, Martins Silva Diniz MD, Almeida da Paixão A. Tomato infrared drying: modeling and some coefficients of the dehydration process. Chil J Agric Res 2012; 72(2): 262-7

[10] Khalifa AJN, Al-Dabagh AM, Al-Mehemdi WM. An Experimental Study of Vegetable Solar Drying Systems with and without Auxiliary Heat, International Scholarly Research Network. Renew Energy 2012; 2012: 1-8.

[11] F Hahn, G Hernandez, J Hernandez, C Perez, and JM Vargas. Optimization of roselle drying time and drying quality. Can Biosyst Eng 2011; 53: 31-8.

[12] Karabacak R, Atalay O. Comparison of drying characteristics of tomatoes with heat pump dehumidifier system, solar assisted system and natural drying. J Food Agric Environ 2010; 8(2):190-4.

[13] Workneh TS, Raghavan V, Gariepy Y. Microwave assisted hot air ventilation drying of tomato slices Paper presented at the Int. Conf. on Food Eng. And Biotechnology. Singapore: IACSIT Press 2011.

[14] Souza JS, Medeiros MFD, Margarida MA, Magalhaes MMA, Rodrigues $\mathrm{S}$, Fernandes FAN. Optimization of osmotic dehydration of tomatoes in a ternary system followed by air-drying. J Food Eng 2007; 83: 501-9.

[15] Heredia A, Barrera C, Andre's A. Drying of cherry tomato by a combination of different dehydration techniques. Comparison of kinetics and other related properties. J Food Eng 2007; 80: 111-8.

[16] Giametta F, Sorrentino E, Lapenna A, La Fianza G. Experimental tests to optimize cheese drying and ripening. Int J Agric Biol Eng 2012; 5(4): 74-84.

[17] Ho JC, Chou SK, Chua KJ, Mujumdar AS, Hawlader MNA. Analytical study of cyclic temperature drying: effects on drying kinetics and product quality. J Food Eng 2002; 49: 271.

[18] Cengel AY. Introduction to thermodynamics and heat transfer. New York, NY, USA: McGraw-Hill Ed. 1997.

[19] Ruiz A, Cuadros F, Lopez-Rodriguez F. Characterization of industrial tomato by-products from infrared drying process. Food Bioprod Process 2009; 87: 282-91.

[20] Ruiz Celma A, Cuadros F, Lopez-Rodriguez F. Convective drying characteristics of sludge from treatment plants in tomato processing industries. Food Bioprod Process 2012; 90: 224-34. 
[21] Mohsenin NN. Physical properties of agricultural materials and food products. NewYork, NY, USA: Routledge Publ., Taylor and Francis Group 1989.
[22] Bird RB, Stewart WE, Lightfoot EN. Transport phenomena. Hoboken, NJ, USA: John Wiley and Sons 2006.

[23] Vega-Mercado P. Advances in dehydration foods. J Food Eng 2001; 49: 271.

Received: March 14, 2013

Revised: May 12, 2013

Accepted: May 15, 2013

(C) Catalano et al.; Licensee Bentham Open.

This is an open access article licensed under the terms of the Creative Commons Attribution Non-Commercial License (http://creativecommons.org/licenses/by-nc/3.0/) which permits unrestricted, non-commercial use, distribution and reproduction in any medium, provided the work is properly cited. 